\title{
Natriuresis After a Water Load in Humans Under Different Sodium Body Content
}

\author{
MARTHA PATRICIA ROSAS-ARELLANO, ALBERTO GUEVARA-ROJAS, ${ }^{1}$ \\ ROSALINDA GUEVARA-GUZMÁN AND LUIS PASTOR SOLANO-FLORES ${ }^{2}$ \\ Departamento de Fisiología, Facultad de Medicina, Universidad Nacional Autónoma de México, \\ Apartado Postal 70250, 04510-México, D. F., México
}

Received 24 March 1992

\begin{abstract}
ROSAS-ARELLANO, M. P., A. GUEVARA-ROJAS, R. GUEVARA-GUZMÁN AND L. P. SOLANO-FLORES. Natriuresis after a water load in humans under different sodium body content. PHYSIOL BEHAV 52(4) 647-653, 1992.-The present study was aimed at observing the diuretic and natriuretic responses after a water load (2\% body weight) in four groups of young

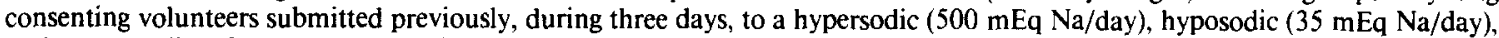
and normosodic ( $200 \mathrm{mEq} \mathrm{Na}$ /day) diet, or treated with furosemide (Lasix, $40 \mathrm{mg} /$ day). During the treatment urine was collected each day. On the fourth day, in the morning, the bladder was emptied, the water load was ingested, and the urine collected during 10 periods of $20 \mathrm{~min}$ each. The urinary, sodium, and chloride flows were determined. The four groups displayed diuretic curves following a similar pattern. In contrast, the natriuretic curves of the four groups were completely different; totally flat with low values for the furosemide group and a large initial natriuretic curve for the hypersodic group with a gradual decrease but maintaining high values. The results indicate that the way the organism compensates for the excess of water by means of urinary water loss is independent of the body sodium content, whereas the way in which sodium loss is accomplished is determined by its body content and is independent of the way in which the water is lost.
\end{abstract}

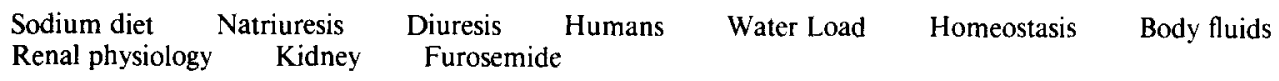

IN mammalian species, such as rat $(12,24)$, dog (11), goat $(1,2,4)$, and sheep (9), it has been observed that the injection of hypertonic $\mathrm{NaCl}$ solution into the third cerebral ventricle rapidly induces a marked and lasting increase in urinary sodium ( $\mathrm{Na}$ ) output. Additionally, in some of these same studies, intracerebroventricular injection of equally hypertonic solutions of other solutes, such as glucose $(1,12)$ or $\mathrm{NH}_{4} \mathrm{Cl}(1)$, were ineffective in that regard. In other studies, the ventriculocisternal perfusion with isosmotic low-sodium solution or hyposmotic low-sodium solution produced a notable decrease of the renal $\mathrm{Na}$ output (25), an increase in plasmatic $\mathrm{Na}$ concentration, and excessive loss of water (8). Furthermore, the natriuresis induced by an intravenous hypertonic $\mathrm{NaCl}$ load could be blocked by lowering the cerebrospinal fluid $\mathrm{Na}$ concentration (8). Finally, the natriuresis observed in normal sheep after water deprivation (22) or after intravenous infusion of hypertonic saline (19) was blocked by ablation of the anterior third ventricle. All these findings, as a whole, suggest that the brain might be involved in the $\mathrm{Na}$ homeostatic mechanisms.

On the other hand, a sudden and prolonged antidiuresis and antinatriuresis are caused by intragastric administration of a wa- ter load equivalent to $10 \%$ of the dog's body weight in the conscious animal. If the water loading is repeated at 4-5-day intervals, the antinatriuretic response remains unchanged, but a gradual increase of the urinary volume turns the initial antidiuretic response into a progressive water diuresis after the fourth or fifth test $(14,15)$. These data indicate that $\mathrm{Na}$ and water excretion can be regulated independently, and also that the corresponding mechanisms interact in harmony to maintain fluid composition under the imposed disturbances. Several authors $(3,13,23)$ have proposed that renal excretion of $\mathrm{Na}$ depends on a specific mechanism that regulates body $\mathrm{Na}$ content. However, no experimental work has been made to study the relationship between $\mathrm{Na}$ and water excretion in humans submitted to body fluid disturbances.

From all the above, if a specific body Na content homeostatic mechanism existed, interacting with a body water content homeostatic mechanism, it follows then that their activity under different body $\mathrm{Na}$ content conditions would be reflected in the urine composition. Particularly, the Na output pattern as well as the water excretion pattern, after body fluids dilution by a water load, would depend on the previous $\mathrm{Na}$ content of the organism.

\footnotetext{
'Deceased, March 4, 1989.

${ }^{2}$ Requests for reprints should be addressed to Luis Pastor Solano-Flores, Department of Physiology, Health Sciences Centre, The University of Western Ontario, London, Ontario, Canada N6A 5Cl.
} 
Hence, the aim of the present work was to determine water and $\mathrm{Na}$ output, plasmatic $\mathrm{Na}$ levels, and blood osmolality after a water loading in normal young humans submitted previously to a 3-day hyper-, hypo-, or normosodic diet. or treated with the natriuretic drug furosemide. The results indicate the existence of a homeostatic mechanism for the body $\mathrm{Na}$ content that seems to operate independently, and in harmony, with the homeostatic mechanism for the body water content.

\section{METHOD}

Experimental subjects were volunteer consenting young medical students of either sex. Their age ranged from 19 to 25 years. Men's weights were $52-80 \mathrm{~kg}$ and their heights, $1.63-1.84$ $\mathrm{m}$. Women's weights were $46-64 \mathrm{~kg}$ and their heights, $1.5-1.65$ $\mathrm{m}$. For the women, the experimental procedures were done at least 9 days after the first day of menstruation. They were also checked to present regular menstrual cycles of 28-30/4 days. All the subjects were apparently healthy, with no pathological medical report, and without present medical treatment. Medical supervision was available during all the phases of the experiment. The subjects participated in the present study as part of their Human Physiology Laboratory course; hence, all the participants were instructed in the theory of the problem and were actively involved in the experimental procedure. Four groups of subjects were formed with equal numbers of men and women: the normosodic diet group (NSG; $n=16$ ), the hyposodic diet group (HYPOSG; $n=8$ ), the hypersodic diet group (HYPERSG; $n=$ 8 ), and the furosemide-treated group (FURG; $n=8$ ). The subjects were submitted to their respective diet or drug treatment during the 3 previous days to the day of the water load. The normosodic and the hyposodic diets were applied as indicated in the diet tables from the Merck Manual (5). The hypersodic diet corresponded to the normal diet but included an additional supply of salty snacks: 10 brine soaked olives or $40 \mathrm{~g}$ of salty cheese during each meal, three times a day and also a package (six pieces) of brine-soaked apricots three times a day. All the subjects had a list of the type and amount of food allowed. In this way, the daily Na intake for the groups was as follows: NSG, 150-200 mEq; HYPOSG, 22-35 mEq; HYPERSG, $500 \mathrm{mEq}$. The FURG group followed the normosodic diet and was given orally a single dose of $40 \mathrm{mg} /$ day of furosemide (28) (Lasix. Química Hoechst de México) before breakfast during the 3 days previous to the day of the water load. All the subjects were allowed to drink no more than 1.51 of tap water daily besides the liquid food (soup, milk, juice, coffee).

All the subjects kept a record of the schedule, quantity, and type of food and liquids ingested. The record was used to verify that the diet directions had been correctly followed. During each of the 3 days of the diet or drug treatment, the subjects collected their 24-h urine in a single flask, one flask for each day. These samples were used as controls. At 0800 , in the laboratory, on the day of the water load, the bladder was emptied. The subjects immediately drank an amount of distilled water equivalent to $2 \%$ of their body weight during no more than 10 min. Every $20-$ min period from the start of the water loading, the bladder was totally emptied. In this way, 10 samples were collected. Three $10-\mathrm{ml}$ venous blood samples were also obtained from the median cubic vein. The first sample was obtained $5 \mathrm{~min}$ before the start of the water load. The second sample was obtained $40 \mathrm{~min}$ after the start of the water load, corresponding this time to the second period of urine collection. The third sample was obtained 70 min after the start of the water load, that is, $10 \mathrm{~min}$ before the time of the fourth period of urine collection had been completed. Plasma samples were processed by conventional centrifugation procedures. The volume of the urine samples was measured and the urine flow (UV, $\mathrm{ml} / \mathrm{min}$ ) was calculated. The urine and plasma Na concentration was determined by flame photometry (Beckman Instruments, DU 2400) and the Na flow $\left(\mathrm{U}_{\mathrm{Na}} \mathrm{V}, \mu \mathrm{mol} /\right.$ $\mathrm{min}$ ) was calculated. Urine $\mathrm{Cl}$ concentration was determined by the Schales and Schales-Brun method (33) and the $\mathrm{Cl}$ low ( $\mathrm{U}_{\mathrm{C}} \mathrm{V}$. $\mu \mathrm{mol} / \mathrm{min}$ ) was calculated. Plasma osmolality was determined by freezing point depression with the aid of an osmometer (Osmette 2007. Precision Systems. Inc.). A two-factor split plot analysis of variance design was used, followed by a post hoc Duncan test for multiple comparisons: $p<0.05$ was taken as the probability level of statistical significance. Data are presented as means.

\section{RESULTS}

Results are depicted in Fig. 1 and Table 1. In the four groups, no statistical intragroup nor intergroup differences were detected in the UV values during the 3 days of diet or furosemide treatment. Except for HYPERSG on the first day, the $\mathrm{U}_{\mathrm{Na}} \mathrm{V}$ values of HYPERSG, HYPOSG, and FURG, during the 3 days of diet or furosemide treatment, were not statistically different from the $\mathrm{U}_{\mathrm{Na}} \mathrm{V}$ values of NSG. The $\mathrm{U}_{\mathrm{Na}} \mathrm{V}$ value of HYPERSG was significantly greater than that of HYPOSG on the first day and greater than that of HYPOSG and of FURG on the third day.

No statistical intragroup differences were observed in $\mathrm{U}_{\mathrm{Na}} \mathrm{V}$ values during the 3 days of diet or furosemide treatment. No statistical intragroup or intergroup differences were observed in $\mathrm{U}_{\mathrm{Cl}} \mathrm{V}$ values during the 3 days of diet or furosemide treatment. Taking into account the above, the $\mathrm{UV}, \mathrm{U}_{\mathrm{Na}} \mathrm{V}$, and $\mathrm{U}_{\mathrm{Cl}} \mathrm{V}$ values for the third day of diet or furosemide treatment were used as controls. In the first 20 -min period of urine collection, following the start of the water loading, the UV values for the four groups were not statistically different from the corresponding UV control values. In the second period, the FURG UV value was still not different from its control value. The diuretic effect due to the water load was already observed in the second period for HYPERSG, HYPOSG, and NSG, and in the third period for FURG. In the fourth period, all the groups reached maximum $U V$ values. Except for the sixth period, in which the HYPERSG UV value was significantly lower than the NSG UV value, the HYPERSG, HYPO, and NSG UV values were not statistically different in each of the 10 periods of urine collection. The FURG group presented UV values significantly lower than the NSG, HYPERSG, and HYPOSG UV values during the second, third, and fourth periods and significantly lower than the NSG values for the fifth and sixth periods. From the seventh period on to the end of the experiment, the UV values of the four groups were not statistically different. The water load was totally excreted by HYPERSG, HYPOSG, and NSG during the seventh period; however. FURG hardly excreted $85 \%$ of the water load on the tenth period of urine collection. In the eighth period, the FURG, HYPERSG, and HYPO UV values reached and maintained the control values. The NSG control UV value was reached on the ninth period.

In contrast to the UV curves, which displayed a similar pattern, the pattern of the $U_{\mathrm{Na}} \mathrm{V}$ curves was statistically heterogeneous among the groups during the experiment. From the first to the last period, the $\mathrm{U}_{\mathrm{Na}} \mathrm{V}$ curve of FURG was maintained flat without differing statistically from its control value. The NSG and HYPOSG $\mathrm{U}_{\mathrm{Na}} \mathrm{V}$ curves were statistically similar during the whole experiment. A significant natriuretic effect was observed in these two groups during the first and second periods; from the third period until the end of the experiment, the $U_{\mathrm{Na}} V$ values were not different from their respective control values. The HY- 

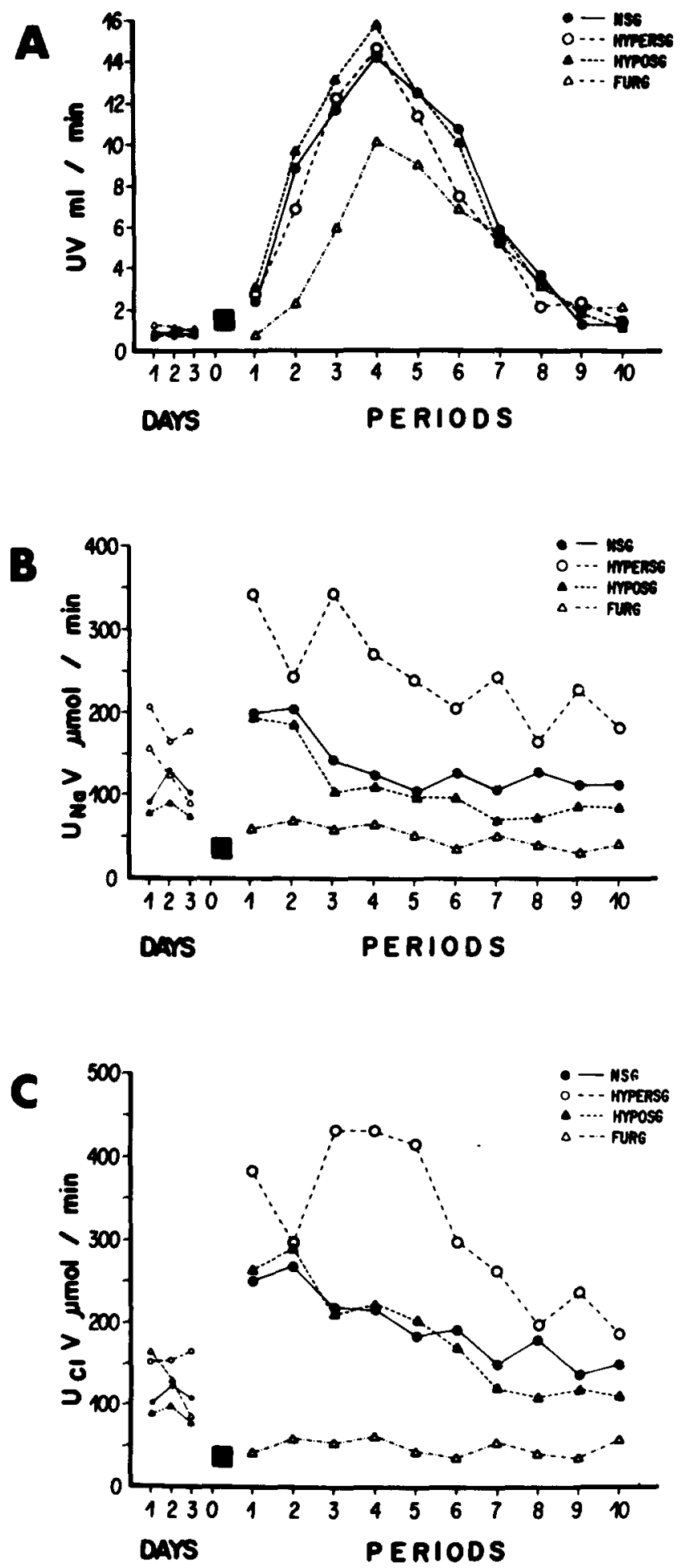

FIG. I. Diuretic (A), natriuretic (B), and $\mathrm{Cl}$ excretion (C) responses after a water load in human subjects under different body Na contents, induced by a hypersodic (O), hyposodic ( $\Delta)$, or normosodic (๑) diet, or furosemide treatment $(\triangle)$. The first three numbers on the abscissa, above the days label, represent the 3 days of diet or furosemide treatment previous to the day of water loading. The 0 in the abscissa represents the moment at which the bladder of the subjects was emptied and the water loading started. Black squares represent the 10 min of water loading. The numbers to the right of 0 represent the 10 successive 20 -min periods of urine collection counted from 0 .
PERSG group displayed a peculiar $\mathrm{U}_{\mathrm{Na}} \mathrm{V}$ curve. A marked natriuresis occurred in the first period followed by a significant reduction of $\mathrm{Na}$ excretion during the second period, reestablishing the control value. In the third period, the natriuretic effect was observed again. From the third period on, a gradual decrease of $\mathrm{Na}$ excretion started to occur, and the control value was reached and maintained from the fifth period on.

In general, the FURG $U_{\mathrm{Na}} \mathrm{V}$ curve kept lower values with respect to the NSG $\mathrm{U}_{\mathrm{Na}} \mathrm{V}$ curve, and the HYPERSG $\mathrm{U}_{\mathrm{Na}} \mathrm{V}$ curve kept higher values. During the whole experiment, the HYPERSG $\mathrm{U}_{\mathrm{Na}} \mathrm{V}$ values were always higher than those of FURG.

In summary, HYPERSG generally presented a natriuretic effect throughout the experiment, whereas FURG presented an antinatriuretic effect with respect to NSG.

The $\mathrm{U}_{\mathrm{Cl}} \mathrm{V}$ curves presented, generally, a pattern parallel to the $\mathrm{U}_{\mathrm{Na}} \mathrm{V}$ curves. The FURG $\mathrm{U}_{\mathrm{Cl}} \mathrm{V}$ curve was practically equal to the $U_{\mathrm{Na}} \mathrm{V}$ curve. The NSG, HYPERSG, and HYPOSG $\mathrm{U}_{\mathrm{Cl}} \mathrm{V}$ curves always maintained higher values as compared to the respective $\mathrm{U}_{\mathrm{Na}} \mathrm{V}$ curves. The HYPERSG $\mathrm{U}_{\mathrm{Cl}} \mathrm{V}$ curve presented a peculiar plateau of high $\mathrm{Cl}$ excretion during the third, fourth, and fifth periods. The time at which the control values of $\mathrm{Cl}$ excretion were reached was delayed with respect to the time at which the control values of $\mathrm{Na}$ excretion had been reached. Thus, the HYPOSG and NSG $\mathrm{U}_{\mathrm{Cl}} \mathrm{V}$ control values were reached in the fifth period, whereas those of HYPERSG were reached in the seventh period.

No intergroup nor intragroup statistical differences were observed for the plasmatic $\mathrm{Na}$ and $\mathrm{Cl}$ concentrations in the three plasma samples of the four groups. Plasmatic Na concentration range was $122.01 \pm 7.83$ to $156.75 \pm 9.63 \mathrm{mmol} / \mathrm{l}$.

Statistical differences were only observed in the plasma osmolality between the first $(312.39 \pm 4.24 \mathrm{mOsm} / \mathrm{kg})$ and the third $(296.95 \pm 5.26 \mathrm{mOsm} / \mathrm{kg})$ sample of HYPERSG and between the third sample of HYPERSG and the third sample of NSG $(308.11 \pm 3.26 \mathrm{mOsm} / \mathrm{kg})$ and HYPOSG (312.19 \pm 9.74 $\mathrm{mOsm} / \mathrm{kg}$ ).

\section{DISCUSSION}

The present study provides experimental evidences in humans that indicate the existence of a homeostatic mechanism for the body $\mathrm{Na}$ content, which seems to operate independently, and in harmony, with the homeostatic mechanism for the body water content.

The composition of body fluids, in a given moment, is determined by the relationship of two components: the solutes and the solvent. This composition can be altered by modifying the input or the output of each or both of these components. However, starting from a given composition, a certain new composition can be attained by different ways. Thus, the status of a body presenting a normal fluid composition can be changed into a hyperconcentrated status by addition of solute or by withdrawal of solvent. In a similar manner, a diluted status can be obtained by withdrawal of solute or by addition of solvent. In the study of body fluids physiology, different experimental models for disturbing any of the components of the body fluids have been used to observe the corresponding compensating actions of the homeostatic mechanisms. For instance, a natriuretic compensating response has been observed in hyperconcentrated animals due to dehydration (21). Urinary $\mathrm{Na}$ retention ensued body fluid dilution by means of rehydration in a dehydrated animal (21). A hypertonic $\mathrm{NaCl}$ intravenous load resulted in a compensating natriuresis (8). A severe antinatriuretic response was produced by a water load $(14,15)$. Manipulation of $\mathrm{Na}$ intake by means of a controlled diet, or manipulation of $\mathrm{Na}$ output by 
TABLE I

SUMMARY OF STATISTICAL DIFFERENCES AMONG GROUPS FOR THE THREE CURVIS OF F.K. I DURING FACH PERIOD OF URINE COLLECTION

\begin{tabular}{|c|c|c|c|c|c|c|c|c|c|c|c|c|c|}
\hline & \multicolumn{3}{|c|}{ Dayss } & \multicolumn{10}{|c|}{ Periods } \\
\hline & I & 2 & 3 & 1 & : & 3 & 4 & $\therefore$ & 6 & 7 & 8 & 9 & 10 \\
\hline UV & & & & & $\begin{array}{l}\bullet \triangle \\
O \Delta \\
\Delta \Delta\end{array}$ & $\begin{array}{l}\triangle \triangle \\
O \Delta \\
\Delta \triangle\end{array}$ & $\begin{array}{l}\triangle \Delta \\
O \Delta \\
\Delta \triangle\end{array}$ & 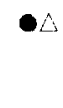 & $\begin{array}{l}\bullet \triangle \\
\bullet 0\end{array}$ & & & & \\
\hline $\mathrm{U}_{\mathrm{Na}} \mathrm{V}$ & $\begin{array}{l}\bullet \\
0\end{array}$ & & $\begin{array}{l}O \Delta \\
O \triangle\end{array}$ & $\begin{array}{l}0 \\
0 \triangle \\
O \Delta \\
O \Delta \\
\Delta \triangle\end{array}$ & $\begin{array}{l}\triangle \triangle \\
O \triangle \\
\triangle \triangle\end{array}$ & $\begin{array}{l}0 \\
-\triangle \\
0 \triangle \\
O \triangle\end{array}$ & $\begin{array}{l}0 \\
O \triangle \\
O \triangle\end{array}$ & $\begin{array}{l}00 \\
0 \Delta \\
O \Delta\end{array}$ & $\begin{array}{l}\bullet 0 \\
\Delta \triangle \\
O \Delta \\
O \Delta\end{array}$ & $\begin{array}{l}00 \\
0 \Delta \\
0 \triangle\end{array}$ & $\begin{array}{l}\bullet \triangle \\
O \Delta \\
O \triangle\end{array}$ & $\begin{array}{l}0 \\
\bullet \triangle \\
O \Delta \\
O \triangle\end{array}$ & $\begin{array}{l}\mathrm{O} \\
\mathrm{O} \triangle\end{array}$ \\
\hline $\mathrm{U}_{\mathrm{C}} \mathrm{V}$ & & & & $\begin{array}{l}0 \\
\bullet \triangle \\
O \triangle \\
\Delta \triangle\end{array}$ & $\begin{array}{l}\triangle \triangle \\
O \triangle \\
\triangle \triangle\end{array}$ & $\begin{array}{l}\bullet 0 \\
\bullet \triangle \\
O \Delta \\
O \triangle \\
\Delta \triangle\end{array}$ & $\begin{array}{l}O \\
\triangle \triangle \\
O \triangle \\
O \triangle \\
\Delta \triangle\end{array}$ & $\begin{array}{l}0 \\
\triangle \triangle \\
O \Delta \\
O \triangle \\
\Delta \triangle\end{array}$ & $\begin{array}{l}\triangle \triangle \\
O \triangle\end{array}$ & $O \triangle$ & $\begin{array}{l}\triangle \triangle \\
O \triangle\end{array}$ & $O \Delta$ & \\
\hline
\end{tabular}

- = NSG; $O=$ HYPERSG; $\Delta=$ HYPOSG: $\Delta=$ FURG

Any paired set of symbols side-by-side indicates that a significant $(p<0.05)$ difference was found between the corresponding two groups for that day or, for that period, for either the $U V . U_{\mathrm{Na}} \mathrm{V}$, or $\mathrm{U}_{\mathrm{Cl}} \mathrm{V}$ curves.

means of the natriuretic drug, furosemide, have been performed to observe the $\mathrm{Na}$ excretion rate after a $\mathrm{Na}$ load (32). In conclusion, the function of the body fluids' homeostatic mechanisms can be manifested through their compensating actions when challenged by disturbances of the body fluid composition under special circumstances. For the present study, these special circumstances consisted of applying a water load to four groups of subjects, which were under different body $\mathrm{Na}$ content conditions. A water load is a sudden maneuver consisting of a supply of water excess to the organism that acutely disturbs body fluid composition and implies body fluid dilution. Different body $\mathrm{Na}$ content conditions can be attained by different semichronic $\mathrm{Na}$ diets or natriuretic drug treatments, which result in a stabilization of the organism $\mathrm{Na}$ content to values that depend on the corresponding $\mathrm{Na}$ intake (6) or $\mathrm{Na}$ output (18). Under these circumstances, the acute excess of water in the organism due to a disturbing water loading is compensated by urinary water loss. The four groups of the present study displayed UV curves following a similar pattern. This fact indicates that the organism is able to compensate for the excess of water by means of urinary water loss in a way that is independent from the semichronic body $\mathrm{Na}$ content condition in which the subject is found at the moment of the disturbing water loading. On the other hand, under these same circumstances, the water loss triggered by the acute excess of water in the organism due to the disturbing water load is used as a vehicle to lose $\mathrm{Na}$ as a compensating action against the semichronic disturbances of body $\mathrm{Na}$ content caused by the diet or natriuretic drug treatment. In the present study, the subjects of FURG were in a severe $\mathrm{Na}$ deficit condition, unable to lose any more Na no matter what the amount of water available. The HYPERSG group, which was in a Na surplus condition, presented an initial marked $\mathrm{Na}$ loss followed by a slow and gradual decrease of $\mathrm{Na}$ excretion, but always presented high values with respect to the other groups. The $\mathrm{U}_{\mathrm{Na}} \mathrm{V}$ curves of these two groups were, then, completely different and were also different from the NSG $\mathrm{U}_{\mathrm{Na}} \mathrm{V}$ curve, which was characterized by an initial natriuresis followed by a marked decrease in the $\mathrm{Na}$ loss to stabilize in the control value. These facts indicate, first, that the way in which the $\mathrm{Na}$ loss is accomplished is determined by the previous condition of body $\mathrm{Na}$ content in which the organism is found at the moment of the disturbing water loading and, secondly, that the way in which $\mathrm{Na}$ is lost is independent from the way in which water is lost. Hence, in the regulation of body fluid composition, two different mechanisms seem to be participating. One is related to water homeostasis and the other is related to Na homeostasis. Both mechanisms seem to operate independently one from the other and in harmony, as suggested by Smith since 1957 (34).

The analysis, as a whole, of the temporal development of the $\mathrm{UV}$ and $\mathrm{U}_{\mathrm{Na}} \mathrm{V}$ curves of the four groups and the relationship among them leads to conferring a physiological meaning to the different events observed in these curves. In this sense, several considerations have to be noted.

For the UV values during the 3 days of diet or drug treatment. no statistical intragroup or intergroups differences were observed. This indicates that the water balance for the four groups was similar during the 3 days of treatment, a situation that was favorable to allow the diet or drug treatment to induce the pretended changes in the body $\mathrm{Na}$ content. The fact that no intragroup statistical differences were observed in the $\mathrm{U}_{\mathrm{Na}} \mathrm{V}$ values during the 3 days of diet or drug treatment for the four groups indicates that the processes responsible to attain a new body $\mathrm{Na}$ content condition, induced by the diet or drug treatment, were already in progress from the first day of treatment. Although the $\mathrm{U}_{\mathrm{Na}} \mathrm{V}$ values of HYPERSG, HYPOSG, and FURG, during the 3 days of diet or drug treatment, were not statistically different from those of NSG, except for HYPERSG on the first day, on the third day statistical differences were observed between the extreme groups, i.e., HYPERSG with respect to HYPOSG and FURG, suggesting that the treatments before the water load maneuver were effective to induce different body Na content conditions, which were reflected in differences in the rate of $\mathrm{Na}$ excretion for that day. In contrast, for the first day of these same extreme groups, HYPERSG and FURG, no differences were found in the $U_{\mathrm{Na}} V$ values, a fact that might be explained considering that both groups, that day, were excreting high $\mathrm{Na}$ 
amounts, one due to the high $\mathrm{Na}$ surplus and the other due to the pharmacological effect of the drug.

Since a water load is totally absorbed in a lapse of $20-30 \mathrm{~min}$ $(27,35)$, and since the first sample of urine was collected 20 min after the start of the water loading maneuver, which lasted 10 min, then during the first period of urine collection, water absorption processes were already in progress. Hence, the amount of water excreted in this first period was still not significantly different from the corresponding control values of the four groups. Nevertheless, some water had already been absorbed and was available for the organism to be excreted. As the organisms of the NSG, HYPOSG, and HYPERSG subjects were in condition to lose $\mathrm{Na}$, that water was used as a vehicle to excrete the excess $\mathrm{Na}$. This excretion was determined by the prevailing body $\mathrm{Na}$ content in which the organism was at the moment of the water load. Thus, HYPERSG presented in this first period a pronounced natriuresis. Both NSG and HYPOSG presented a less marked natriuresis, and FURG maintained a low $\mathrm{Na}$ excretion. From the pronounced natriuresis of $\mathrm{HY}$ PERSG and the low Na excretion by FURG in the first period, it can be inferred that as a consequence of the diet and drug treatment, respectively, the organisms reached a new status of body $\mathrm{Na}$ content in which the homeostatic mechanisms were forced to function semichronically. The one, in the status of high $\mathrm{Na}$ surplus, was able to promptly lose $\mathrm{Na}$ as soon as water was available. The other, in a status of severe $\mathrm{Na}$ deficit, was unable to lose any more $\mathrm{Na}$, no matter what the amount of water available.

During the second 20-min period of urine collection, the absorption of water had been completed and, hence, a maximal dilution of the body fluids should have been accomplished during that period. A clear and similar diuretic effect due to the water load was already observed in HYPERSG, HYPOSG, and NSG. During this period, the organism was forced to perfect the detection of the cause of the disturbance. Since a solution in a container can be diluted either by withdrawal of a certain amount of solute or by solvent addition, then two possibilities for the disturbances had to be tested as cause of the dilution. As the process of detection of the cause of the disturbance was being carried out, an apparently urgent action was taken by HYPERSG, consisting of restraining the excretion of $\mathrm{Na}$; that is, the natriuresis was stopped in such a way that the $\mathrm{Na}$ excretion control value was reestablished. Regarding FURG, a marked delay of water excretion was observed and, as a matter of fact, the UV value was not statistically different from its control value. The Na excretion was maintained low, probably because the organism was in a severe $\mathrm{Na}$ deficit. For NSG, which was not forced to attain a new status of body Na content by a diet treatment, it seems that the detection of the cause of the dilution of body fluids had been overcome and, hence, the available water was used to excrete a slight $\mathrm{Na}$ excess, so that the natriuresis established in the first period was maintained during the second one. The same occurred with HYPOSG.

During the third period of urine collection, it seems that the cause of the dilution of the body fluids had been totally localized as an excess of water. In this condition, HYPERSG, which was in a Na surplus condition, reestablished the natriuresis observed in the first period. It is until this third period that a significant water excretion was observed for the first time in the UV curve of FURG, although the UV value was notably lower than the UV values of HYPERSG, HYPOSG, and NSG. This water was not used to lose $\mathrm{Na}$, since FURG was in a severe $\mathrm{Na}$ deficit, so that $\mathrm{Na}$ excretion was maintained low. It is interesting to point out that in this third period a notable difference of the body fluids' homeostatic mechanism activity was manifested by $\mathrm{HY}$ -
PERSG, HYPOSG, and NSG; that is, whereas the diuretic activity was similar for HYPERSG, HYPOSG, and NSG, HYPERSG presented a marked natriuretic activity and HYPOSG and NSG showed a marked suppression of natriuresis in such a way that the control values were reached. This fact indicates that $\mathrm{Na}$ excretion is not dependent on the way the water excretion occurs, suggesting that two different mechanisms participate in the regulation of body fluids' composition: one related to water homeostasis and the other to $\mathrm{Na}$ homeostasis. In this way, $\mathrm{HY}$ PERSG, HYPOSG, and NSG homeostatic mechanisms for water balance were working in a similar way to compensate for a common disturbance; that is, excrete a water excess, whereas the activity of the correspondent homeostatic mechanism for body $\mathrm{Na}$ content was depending on its respective body $\mathrm{Na}$ status in which the organism was at the moment of the water loading. Additionally, the water homeostatic mechanism seems to function independently from that of $\mathrm{Na}$, as inferred by the fact that FURG excreted only the water excess (the cause of body fluids dilution) but maintained low $\mathrm{Na}$ excretion.

In the fourth period of urine collection, all the groups presented the maximal water excretion rate. The UV values for HYPERSG, HYPOSG, and NSG were again similar. Although FURG's UV value had reached its maximum, it was notably lower than in the other groups. From this period on, a gradual decrease of water excretion occurred in all the groups, with a tendency of the UV curves to behave similarly, a condition that was reached totally in the seventh period and maintained until the end of the experiment. During this fourth period, HYPERSG started a gradual decrease of the natriuretic activity until the control value was reached and maintained from the fifth period on. Both NSG and HYPOSG maintained, until the end of the experiment, the Na excretion values reached previously during the third period. As from the start of the experiment, FURG maintained a low Na excretion until the end of the experiment. Again, it is interesting to point out that the water excretion pattern was similar for all the groups during the descending phase of the UV curves and, as a matter of fact, all the Na diet groups excreted the water load during the seventh period of urine collection with no statistical differences. However, the way $\mathrm{Na}$ was excreted, during these same periods, depended on the body $\mathrm{Na}$ status. Thus, HYPERSG maintained, in general, a high $\mathrm{Na}$ excretion with respect to NSG, and FURG maintained a low $\mathrm{Na}$ excretion. These findings further support the suggestion that the activity of a $\mathrm{Na}$ homeostatic mechanism is not dependent on the water homeostatic mechanism. Furthermore, since the ascending phase of the FURG UV curve was delayed with respect to the other groups, it could be thought that the effector actions of the water homeostatic mechanisms for this group were subjected to the higher priority need of maintaining as low as possible the $\mathrm{Na}$ excretion and, as a matter of fact, at the end of the experiment FURG had hardly excreted $85 \%$ of the water load.

Plasmatic Na concentrations were not statistically different among the three samples of the four groups nor were differences detected among them. This fact indicates that body fluid disturbances, under the conditions of the present study, are not reflected in the plasmatic Na levels, so it seems that the disturbances at the plasmatic level rapidly fade out, probably in a way as stated elsewhere (29) considering “. . . that water diffuses freely across cell membranes in response to an osmotic gradient. Thus, if extracellular osmolality rises due to loss of water or an increase in solutes, water diffuses rapidly from the intracellular to the extracellular space until osmotic equilibrium is re-established at a new, somewhat higher level. Conversely, if extracellular osmolality falls due to addition of water or loss of solute, water diffuses rapidly into cells until osmotic equilibrium is again 
re-established at a lower level." No Na plasmatic differences were found between normal rats submitted to a high $\mathrm{NaCl}$ diet and basal $\mathrm{NaCl}$-diet animals during the 2 weeks of treatment (26). The plasmatic osmolality, in general, measured in the three samples of the four groups did not show statistical differences. Only the HYPERSG third sample osmolality was significantly lower than that of the HYPERSG first sample value, and was also lower than the third sample osmolality of NSG. Plasmatic differences were detected in the third sample, but only in the osmolality of HYPERSG and not in Na concentration. This decrease in osmolality was not due to a decrease in plasmatic $\mathrm{Na}$ but might have been due to another factor. For instance, the moment at which the third blood sample was obtained. although $\mathrm{Na}$ excretion rate of HYPERSG was already in a decreasing process, $\mathrm{Cl}$ excretion rate was stabilized in a plateau that lasted 30 min more; thus, other cations, besides $\mathrm{Na}$, could be accompanying the excreted $\mathrm{Cl}$. and this action is reflected as a lowering of plasma osmolality.

Since the $U_{C l} V$ values for the Na diet groups kept, in general, a parallel pattern to the $U_{\mathrm{Na}} \mathrm{V}$ values but always higher, different cations must be excreted besides $\mathrm{Na}$. However, $\mathrm{U}_{\mathrm{Cl}} \mathrm{V}$ and $\mathrm{U}_{\mathrm{Na}} \mathrm{V}$ curves practically overlapped for FURG, a fact indicating that the organisms of these subjects, in a severe Na deficit, were retaining as much as possible any ion that could be useful to maintain the tonicity of body fluids. It is unlikely that $\mathrm{Cl}$ excretion reflects the actions of the homeostatic mechanisms for body fluid tonicity, since it has been shown that the dipsogenic effect of intracerebroventricular infusion of hypertonic $\mathrm{NaCl}$ is mediated mainly by the $\mathrm{Na}$ ion rather than the $\mathrm{Cl}$ ion (30).

The UV and $U_{\mathrm{Na}} \mathrm{V}$ curves of HYPOSG were parallel to the corresponding NSG curves with no statistical differences. This fact suggests that although the subjects of HYPOSG were submitted to a low $\mathrm{Na}$ intake, their organisms were able to retain any amount of $\mathrm{Na}$, no matter how low it might have been, at least under the present conditions, so that the actions for $\mathrm{Na}$ retention in front of a low $\mathrm{Na}$ intake were very efficient to compensate for the low $\mathrm{Na}$ intake.

Two notable events were observed in the two most stressed groups by the treatments; one was the restraining of $\mathrm{Na}$ excretion presented during the second period in the HYPERSG $\mathrm{U}_{\mathrm{Na}} \mathrm{V}$ curve, and the other was the delay of the onset of the FURG; UV curve. These facts indicate that, although the organisms of these subjects were capable to compensate for the body fluids disturbances, their homeostatic mechanisms required some more time to detect the cause of the disturbance to start the appropriate compensating actions: probably their homeostatic mechanisms were not working at optimal conditions.

It is interesting to point out that the organism of the subjects of HYPERSG, although capable of losing high amounts of $\mathrm{Na}$ with low amounts of water, as shown during the first period of urine collection after the water load, did not use this considerable amount of available water to maintain a high rate of Na excretion. The HYPERSG $U_{\mathrm{Na}} \mathrm{V}$ curve presented a gradual decrease until it was stabilized at the control value from the fifth period on. Nevertheless, during these periods, in general, the natriuretic activity of HYPERSG was higher as compared to that of NSG. This fact suggests the idea that the subjects of HYPERSG, in contrast to those of NSG, had been adapted to a different physiological operative level of $\mathrm{Na}$ excretion induced by the high $\mathrm{Na}$ intake treatment. In this way, the present study provides further information to be considered in the argumentation on understanding whether the body $\mathrm{Na}$ is regulated about a single setpoint or is regulated about steady states. which vary depending on the intake of $\mathrm{Na}(6.7 .10 .16-18.31)$.

Finally, it is likely that the effector actions for $\mathrm{Na}$ excretion. reported in the present work, are controlled at central nervous system levels. In this regard. brain involvement in the regulation of renal sodium excretion has been clearly demonstrated $(8.20)$.

In conclusion, the present study has proven that the experimental model used to disturb body fluid composition was successful to evidence the compensating action of two different body fluids homeostatic mechanisms that in harmony, operate independently one from the other.

\section{ACKNOWLEDGEMENTS}

The authors are fully indebted to Dr. Roberto Agustin Prado Alcalá for his friendly and professional assistance in the statistical analysis. The first author was supported by CONACYT Doctoral Fellowship No. 47969. This work was supported in part by CONACYT \#41 and by PADEP: POSGRADO MED-901.

\section{REFERENCES}

1. Andersson, B.; Jobin, M.; Olsson, K. A study of thirst and other effects of an increased sodium concentration in the 3rd brain ventricle. Acta Physiol. Scand. 69:29-36; 1967.

2. Andersson, B.; Dallman, M. F.; Olsson, K. Evidence for a hypothalamic control of renal sodium excretion. Acta Physiol. Scand. 75: $496-510 ; 1969$.

3. Andersson, B. Regulation of body fluids. Annu. Rev. Physiol. 39: $185-200 ; 1977$.

4. Andersson, B.; Leksell, L. G.; Lishajko, F.; Rundgren, M. Cerebral sodium-noradrenaline interaction: Dipsogenic, antidiuretic and natriuretic effects. Acta Physiol. Scand. 102:254-256; 1978.

5. Berkow, R.; Talbott, J. H., editors. El Manual Merck de Diagnostico y Terapeutica. Seccion 11 . Trastornos nutricionales y metabolicos. Rahway, NJ: Merck \& Co., 1981:1207-1225.

6. Bonventre, J. V.; Leaf, A. Sodium homeostasis: Steady states without a set point. Kidney lnt. 21:880-882; 1982.

7. Bonventre, J. V.; Leaf, A. Response of Drs. Bonventre and Leaf. Kidney Int. 21:885; 1982.

8. Chodobski, A.; McKinley, M. J. Cerebral regulation of renal sodium excretion in sheep infused intravenously with hypertonic $\mathrm{NaCl} . \mathrm{J}$. Physiol. 418:273-291; 1989.

9. Cox, P. S.; Denton, D. A.; Mouw, D. R.; Tarjan, E. Natriuresis induced by localized perfusion within the third cerebral ventricle of sheep. Am. J. Physiol. Regul. Integr. Comp. Physiol. 252(21):R 1R6; 1987.

10. Daniels, F. H.; Cortell, S.; Leonard, E. F. Formulating and evaluating quantitative models of control of sodium stores. Am. J. Physiol. Regul. Integr. Comp. Physiol. 249(18):R624-R633; 1985

11. Dorn, J. B.; Levine, N.: Kaley, G.; Rothballer, A. B. Natriuresis induced by injection of hypertonic saline into the third cerebral ventricle of dogs. Proc. Soc. Exp. Biol. Med. 131:240 242; 1969.

12. Dorn, J.; Porter, J. C. Diencephalic involvement in sodium excretion in the rat. Endocrinology 86:1112-1117; 1970.

13. Fitzsimons, J. T. Bengt Andersson's pioneering demonstration of the hypothalamic "drinking area" and the subsequent osmoreceptor/ sodium receptor controversy. Acta Physiol. Scand. 136(Suppl. 583): $15-25 ; 1989$.

14. Guevara-Rojas, A. Efecto de la ingestión restringida de agua y de la sobrehidratación sobre la excreción de agua y sodio. Gac. Med. Mex. 108:141-151; 1974

15. Guevara-Rojas, A. El líquido extracelular y la regulación central del agua y del sodio. Bol. Estud. Med. Biol. 33:65-76; 1984/1985.

16. Hollenberg, N. K. Set point for sodium homeostasis: Surfeit, deficit, and their implications. Kidney Int. 17:423-429; 1980.

17. Hollenberg, N. K. Surfeit, deficit, and the set point for sodium homeostasis. Kidney Int. 21:883-884, 1982. 
18. Ledingham, J. M.; Simpson, F. O. Handling of a sodium load by rats on a low sodium intake and frusemide. Clin. Exp. Pharmacol. Physiol. 14:243-246; 1987.

19. Lichardus, B.; McKinley, M. J.; McDougall, J. G. et al. Ablation of the anterior wall of the third ventricle suppresses natriuresis in response to hypertonic saline loading in sheep. Physiol. Bohemoslov. $34: 439 ; 1985$.

20. Lichardus, B.; Okolicany, J.; McKinley, M. J.; Denton, D. A.; Ponec, $\mathrm{J}$. Brain involvement in the regulation of renal sodium excretion. Klin Wochenschr. 65(Suppl. 8):33-39; 1987

21. McKinley, M. J.; Denton, D. A.; Nelson, J. F.; Weisinger, R. S. Dehydration induces sodium depletion in rats, rabbits, and sheep. Am. J. Physiol. Regul. Integr. Comp. Physiol. 245(14):R287-R292; 1983.

22. McKinley, M. J.; Denton, D. A.; Park, R. G.; Weisinger, R. S. Cerebral involvement in dehydration-induced natriuresis. Brain Res. 263:340-343; 1983.

23. McKinley, M. J.; Denton, D. A.; Coghlan, J. P. et al. Cerebral osmoregulation of renal sodium excretion-a response analogous to thirst and vasopressin release. Can. J. Physiol. Pharmacol. 65:1724$1729 ; 1987$.

24. Morris, M.; McCann, S. M.; Orias, R. Evidence for hormonal participation in the natriuretic and kaliuretic responses to intraventricular hypertonic saline and norepinephrine. Proc. Soc. Exp. Biol. Med. 152:95-98; 1976.

25. Mouw, D. R.; Vander, A. J. Evidence for brain Na receptors controlling renal Na excretion and plasma renin activity. Am. J. Physiol. 219:822-832; 1970.

26. Mozaffari, M. S.; Jirakulsomchok, S.; Oparil, S.; Wyss, J. M. Changes in cerebrospinal fluid $\mathrm{Na}+$ concentration do not underlie hyperten- sive responses to dietary $\mathrm{NaCl}$ in spontaneously hypertensive rats. Brain Res. 506:149-152; 1990.

27. Olsson, K.; Benlamlih, S.; Dahlborn, K.; Fyhrquist, F. Effects of water deprivation and hyperhydration in pregnant and lactating goats. Acta Physiol. Scand. 115:361-367; 1982.

28. Quamme, G. A. Loop diuretics. In: Dirks, J. H.; Sutton, R. A. L., eds. Diuretics: Physiology, pharmacology \& clinical use. Philadelphia: W. B. Saunders; 1986:86-116.

29. Robertson, G. L. Thirst and vasopressin function in normal and disordered states of water balance. J. Lab. Clin. Med. 101:351-371; 1983.

30. Rundgren, M.; Denton, D. A.; McKinley, M. J.; Weisinger, R. S. The dispogenic effect of intracerebroventricular infusion of hypertonic $\mathrm{NaCl}$ in the sheep is mediated mainly by the $\mathrm{Na}$ ion. Acta Physiol. Scand. 127:433-436; 1986.

31. Simpson, F. O. Sodium intake, body sodium, and sodium excretion. Lancet 2:25-29; 1988 .

32. Simpson, F. O.; Ledingham, J. M. Surfeit and deficit of sodium: Evidence from studies of body sodium in rats. Nephron 54:61-69; 1990.

33. Smith, H. W. Principles of renal physiology. New York: Oxford University Press; 1956:214.

34. Smith, H. W. Salt and water volume receptors. An exercise in physiologic apologetics. Am. J. Med. 23:623-652; 1957.

35. Verney, E. B. The antidiuretic hormone and the factors which determine its release. Proc. R. Soc. Lond. [Biol.] 135:25-106; 1947. 